\title{
EN EL PORTICO DEL TEMPLO DE APOLO
}

\author{
(IN THE PORTICO OF THE TEMPLE OF APOLLO)
}

\author{
Antonio Fernández Alba, Arquitecto \\ Académico de la Real Academia de Bellas Artes de San Fernando
}

Fecha de recepción $8-X-88$

\section{RESUMEN}

El presente artículo plantea conceptos interesantes en el dominio de la filosofía del arte, en especial del arte arquitectónico. A partir de la etimología, su autor propone considerar la Arquitectura como un recorrido o itinerario de iniciativas figuradas, y considera que la proyección en ese campo lleve implicita la facultad de imaginar formas que sobrepasan la realidad. El trabajo, denso en conceptos sutiles, estudia el modo de proyectar actual en el contexto de la Historia de la Arquitectura, considerado como arte y como técnica.

\section{SUMMARY}

This article sets out interesting concepts in the sphere of philosophy of ant, and in particular of architecture. Basing himself on etymology, its author proposes a view of architecture as a course or itinerary of initiatives expressed figuratively, and feels that the drawing up of plans in this field involves implicitly the faculty of imagining forms which extend beyond reality. This study, containing a great many sutle concepts, looks at today's way of planning in the context of History of Architecture, considering it as art and as a technical matter.
"Si la belleza es la única provincia legítima del poema", en expresión de E. Allan Poe. La duda se presenta como el territorio apropiado para imaginar el proyecto de la arquitectura, que como su origen filológico expresa: ARCH es comienzo, iniciativa, dirección; completándose el término TEKTON, como invención, configuración, solidificación.

Por tanto, la arquitectura vinculada a la fidelidad de sus origenes se deberia entender como un itinerario de invenciones, como supuesto de iniciativas figuradas, coherencia de la materia trascendida, una Suma de actividades creativas; en definitiva como: "el arte de construir con solidez científica y con elegancia no caprichosa", en el buen decir de los arquitectos del pasado (Lódoli entre otros). Existe una opinión ampliamente difundida y compartida, según la cual el arte de imaginar el espacio de la Arquitectura concluye en su escritura. Algunos, incluso tal aserto lo consideran revolucionario.

El proyecto de la arquitectura lleva implícita la facultad de imaginar, imaginar FORMAS en el espacio que sobrepasan la realidad para después edificarlas en la propia realidad y es, o resulta ser, facultad imaginativa (iniciática, invención), la que permite prefigurar nuevas formas para el discurrir de la vida, anticipar ámbitos espaciales apropiados a la biografía del ser humano 0 recurrir por mediación del espacio a configurar el cúmulo de ensoñaciones materiales donde poder verificar la acción, de la que es solidaria la existencia. El arte de la Arquitectura es constructivo por naturaleza, por eso la audacia de sus conquistas suele quedar reflejada en el trabajo alrededor de la materia, por lo general atareada ésta en superar los límites de la expresión geométrica.

Siempre fue hermoso para el trabajo del hombre mostrar cómo es posible hacer surgir las cosas, imaginar el lugar y atribuirle el inaudito poder de la transformación. Atendiendo a tales resonancias se hace impres. cindible evidenciar las falsificaciones proclives a confundir las prerrogativas del lugar.

El ejercicio de la arquitectura, la construcción de sus espacios son legitimos en la medida de su autenticidad, pero discriminar las formas auténticas de los valores ficticios, en tiempos de snobismo y simulacro, no es tarea recomendable por la fatiga que exige acotar la novedad. 


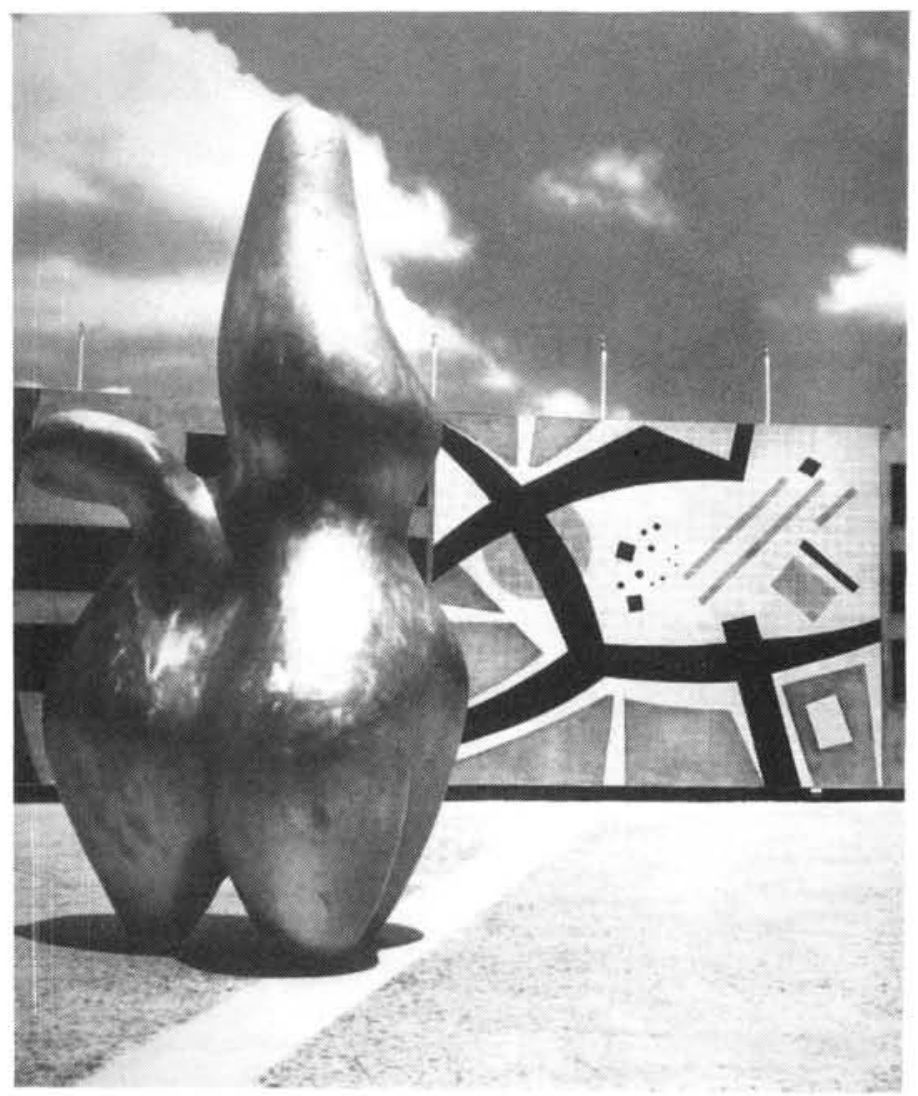

La novedad se instala en los ambiguos territorios de la creatividad y se intuye como el resultado de la originalidad. No hay mayor engaño que pensar o creer que la auténtica originalidad es mera cuestión del impulso de la inspiración; cuando originar en arquitectura consiste en combinar, eso sí, con paciencia y esmero, el territorio legítimo del espacio, que resulta no ser otro que el de la Belleza.

Generalmente, cuando hablamos de belleza en arquitectura no se pretende resaltar una cualidad, sino percibir un efecto, porque como es bien sabido la suma de percepciones, que acerca de un espacio tenemos, nos aumenta el efecto y los efectos alimentan sobremanera la satisfacción del sentimiento; mientras que la cualidad de un espacio tiende a gratificar el intelecto.

La arquitectura, como el arte, es una manera de hacer obras según ciertos métodos alcanzados, bien por invención o aprendizaje. El método, si se quiere, resulta ser un itinerario limitado pero que asegura la aproximación al hallazgo y confirma la validez del discurrir de lo pensado.

Nos encontramos hoy frente a un modo de proyectar la arquitectura donde los modelos (o maneras) han desaparecido, $y$ tal ausencia impide el que nos podamos apoyar en identidades espaciales prefiguradas, de ahi las peregrinaciones hacia los fragmentos del MODELO.
Esta lectura del fragmento inclina al proceder del arquitecto hacia una tendencia generalizada, que induce a contemplar el pasado para reproducirlo.

Pero, como toda visión de las cosas sometida a la graduación de planos, nuestra percepción es más fina en las primeras secuencias, y a medida que se alejan los perfiles y formas que dieron vida y significado a tales espacios, éstos van desapareciendo. Tal proceder reproductivo entretiene al proyecto en repetir modelos "históricamente imposibles". La teoría de la imitación, que tal proceder sustenta, apuesta por diseñar un objeto arquitectónico donde poder añadir las manifestaciones arbitrarias, intuitivas, emocionales de la convención formal; su resultado son las aproximaciones hacia las Arquitecturas de la diferencia, la descomposición o la paradoja.

Del pasado no heredamos más que fragmentos dispersos, y una parte importante del proyecto actual intenta formalizar los espacios vacios con redundancias históricas. ¿Qué innovación representan las caligrafías pautadas de un $\mathrm{P}$. Eiseman, sino añadir la descomposición vaga y compleja al soporte racional-funcionalista de los períodos iniciales del M. ${ }^{\circ}$ M.?

Semejante modo de proceder no debe conducir ni a la mitificación escolar, ni a su censura; anotemos que itinerarios semejantes no aportan indagaciones concre- 


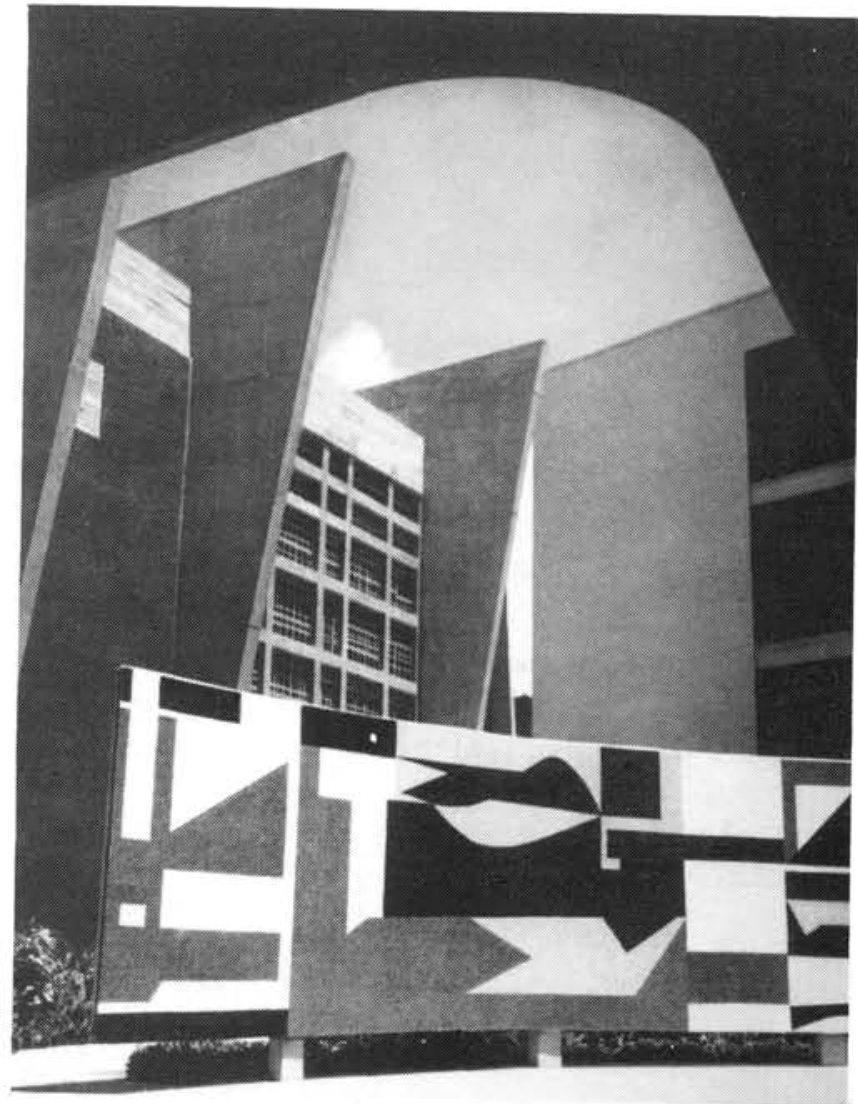

tas, ni revelan conocimientos precisos, su caligrafía acentúa con apóstrofes sordos su pretendida originalidad.

\section{REGENERACION ARTISTICA DE LA ARQUITECTURA}

La deculturización tecnocrática ha llegado a invadir, entre otros, los dominios del pensamiento arquitectóni$\mathrm{co}, \mathrm{y}$ ante tal exclusión parece que se suscita una demanda generalizada: Recuperar la arquitectura como Arte, es decir, como comienzo, iniciativa, dirección, e inscribirla en los dominios de la segunda Naturaleza Técnica.

La arquitectura acumula en la consolidación de sus formas las expresiones fragmentarias a que tal proceso conduce. Como bien sabemos, el proceso creador presupone en su origen el sentimiento de un descubrir, por tanto existe en el arquitecto la necesidad de inventar; la invención lleva implícito el desarrollo de la imaginación, pero no debe de confundirse aquello que se imagina; lo imaginado no tiene por qué necesariamente reflejarse en una forma concreta; no así la invención, que resulta inconcebible sin adoptar una forma explicita. En tal situación crítica parece necesario "moralizar el diálogo entre la imaginación y la invención, para que ninguno de los interlocutores de la arquitectura se quede fuera", parafraseando el testimonio de Haber- mas; pero con la condición de que tal diálogo se aleje de las "arquitecturas crepusculares" tan en boga en la actualidad. La demanda artística para la arquitectura la presenciamos hoy como la necesidad de hacer resurgir los valores simbólicos después del derrocamien. to de lo funcional. Este proyecto simbólico viene consumado por una élite de "filisteos en arrebato", de "clérigos adelantados", cuyos espacios ("objetos de melancolia") nos pretenden confabular con la idea que vivimos en un tiempo de "Rosas y Azucenas", y habitamos la "Torre de las mil lenguas" en el imperio de la razón muerta. La dura experiencia del pensamiento en arquitectura ha sido siempre una especulación libre y no deberia aceptar como válido tanto historicismo vano, ni tan redundante epidermis simbólica, confabulado alrededor de las crónicas del periodismo gráfico.

Porque no se trata de reducir el proyecto de lo arquitectónico a una cuestión de signos, ni de tener que aceptar el maniqueísmo moderno de dualidades exclusivas: Abstracción (v) Realismo, Arcaísmo (v) Modernidad, Fascinación por la historia (v) Religiones postmodernas, Nuevo reginalismo (v) Estilo internacional. Pues no existe un Modelo arquitectónico moderno que se pueda codificar en ley ni hacerse explícito en la unidad de estilo una heterogeneidad de estilos, elemen. tos simbólicos, de espacios y formas dispares y contradictorias que pertenecen tanto a la tradición como a la modernidad es lo que constituye la nueva concien. 


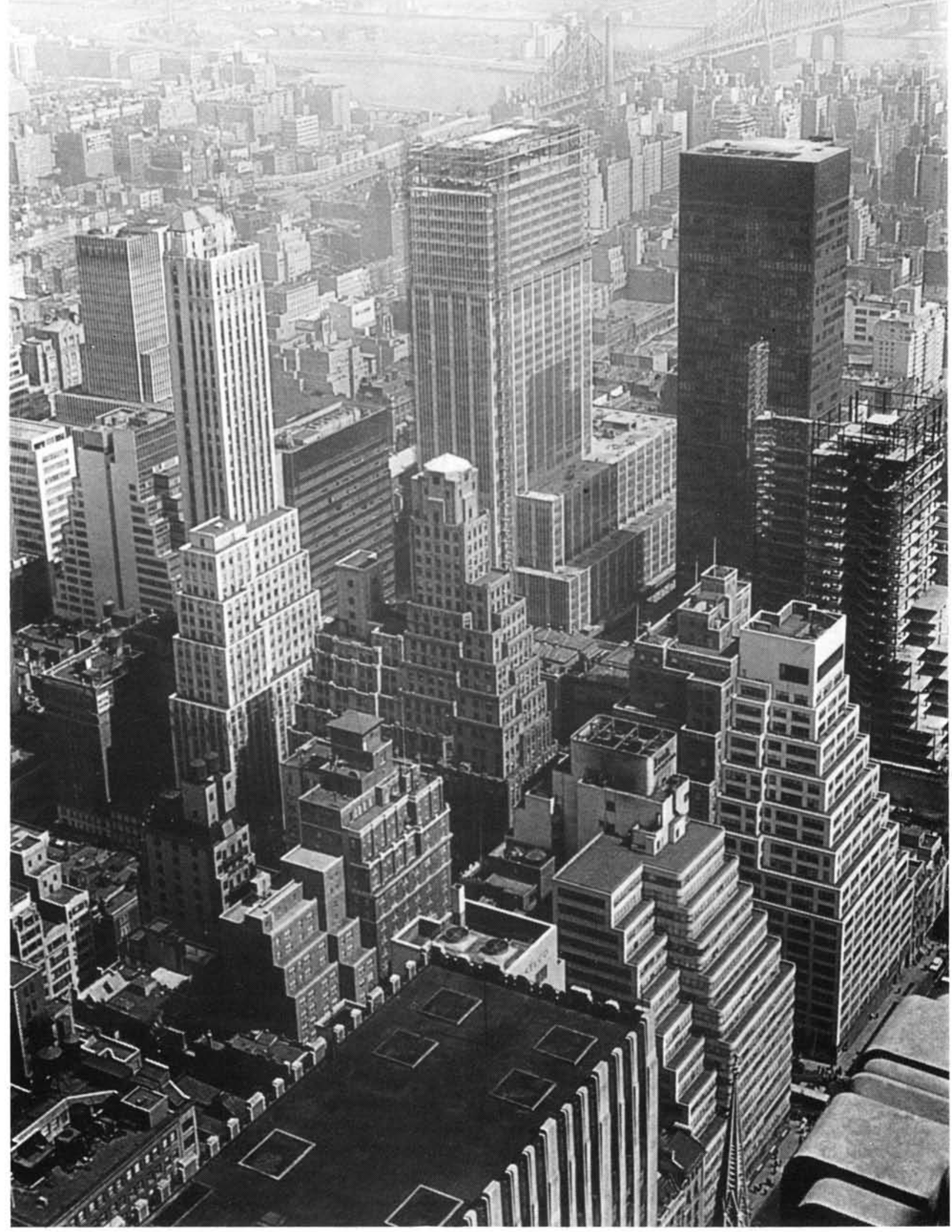




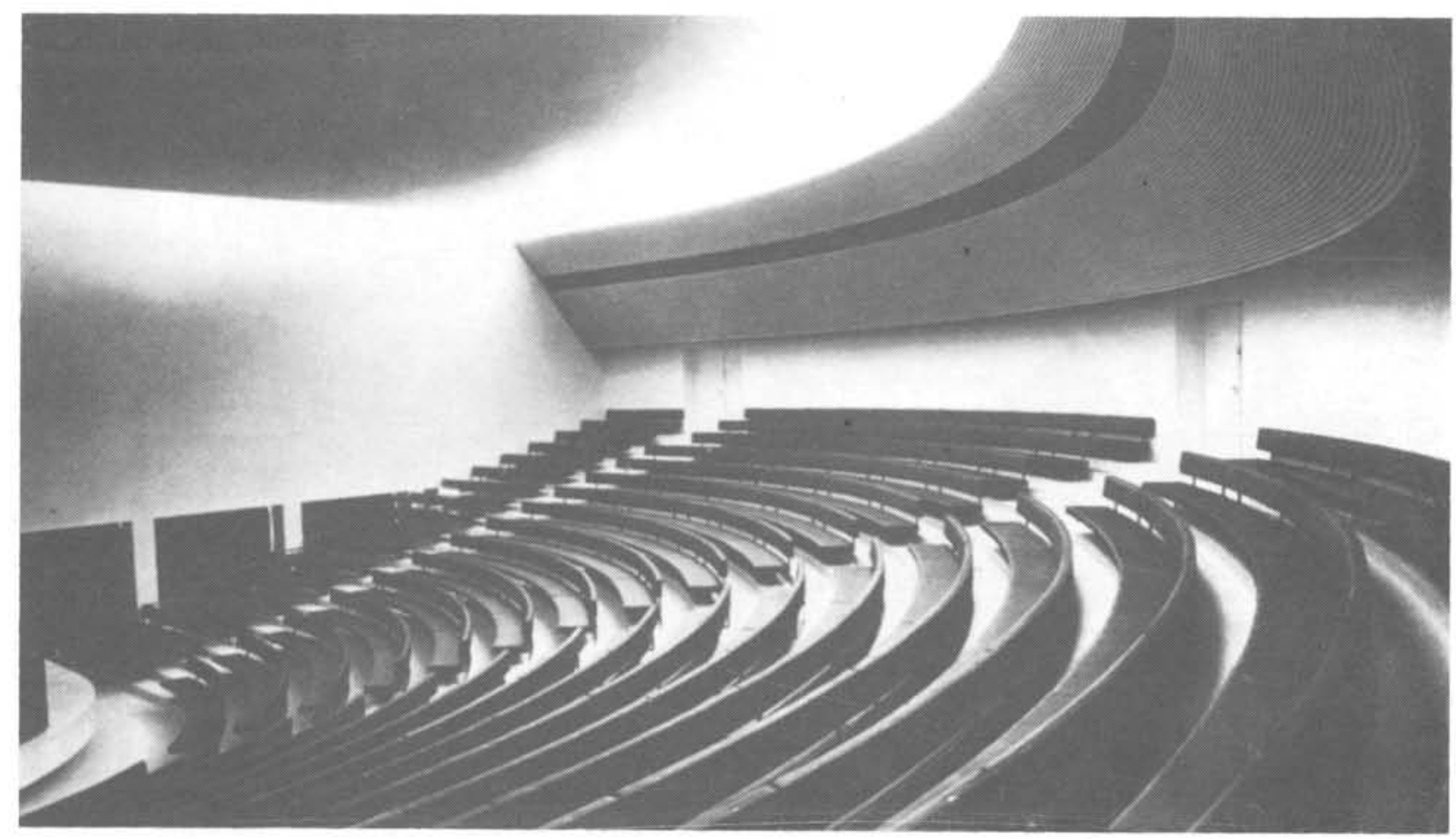

cia artística acosada por el esfuerzo que representa el enunciar los resultados de una síntesis, por verificar, entre "arquitectura de consumo" y "élite cultural". Las vicisitudes que tal proceso comporta quedan muy bien reflejadas en Erasiego de imágenes, en su lúdica procacidad formal. Imágenes y formas donde sólo se solicita la mera presencia perceptiva, espacios donde sólo se trafica con la decoración de la apariencia o la exhibición modal. Tal vez porque atrapados por un pensamiento que favorece "el pragmatismo de la técnica operativa y de la manipulación" (Heidegger), apenas le queda resquicio al arquitecto para comprender que el objeto representado debe estar cerca del ojo, y poder ser reconocido en su grandeza verdadera; que la dimensión perceptiva de la perspectiva debería tener su punto de fuga alli donde el espacio se contempla con la "mirada interior", como desaba Plotino, porque es precisamente esta mirada la que permite la revelación del reflejo de lo invisible. Se trata por tanto no de representar lo que se ve, sino lo que se piensa "En la época que nosotros inventamos el cubismo, señala Picasso, trabajando entonces como un excelente pintor figurativo, no se trataba de hacer cubismo sino de poder experimentar aquello que estaba en nosotros".

Cuando se contempla la arquitectura desde los rescoldos avivados de la "memoria involuntaria" las imágenes de las arquitecturas de autor o la multiplicación de los objetos de uso cotidiano que acuden a las páginas de las publicaciones en boga surge la idea de si esta exhibición de edificios mórbidos y rutilantes objetos de simulacro no se congratulan entre si en un diálogo con las "pulsaciones" de la muerte. Junto a esta posible explicación tanática de la última arquitectura, al lado de estos espacios de simulacro final, la insinuación, el ensayo, la experimentación de las formas simbólicas acuden como categorias y, en ocasiones, como afirmaciones autoritarias para intentar salvar los lugares donde habita el hombre en tiempo de crisis general de los valores.

La gran interrogación para el arte de la arquitectura sigue aún abierta, el preguntar como certeramente señala M. Heidegger, es la devoción del pensamiento ¿Cuál es el lugar de la arquitectura en los territorios ocupados por la técnica moderna? ¿Dónde está escrito que sea sólo el arquitecto quien ha de formalizar el espacio? ¿Acaso la técnica del siglo que, como señala el filósofo, es algo que el hombre no puede dominar, incita al abandono de las grandes creaciones del espacio? ¿Si todo en el espacio técnico funciona sin la presencia de sus signos, ha de ser la recuperación del símbolo el vínculo que ilumine la verdad interior? ¿Acaso el confort resuelve el desarraigo y destrucción de las geografias naturales que comparten los seres humanos?

Los espacios de la arquitectura de esta modernidad institucionalizada se construyen bajo la tutela de estos arquitectos, al margen de las demandas de la racionalidad crítica, ignorando o pretendiendo ocultar el poder de ruptura que significó el "imaginario técnico", donde tuvo su origen el universo de objetos que perturban hoy nuestra identidad, haciéndonos creer que no existe lugar que "requiera cuidado"; Holderlin con poética precisión lo habia descrito: 


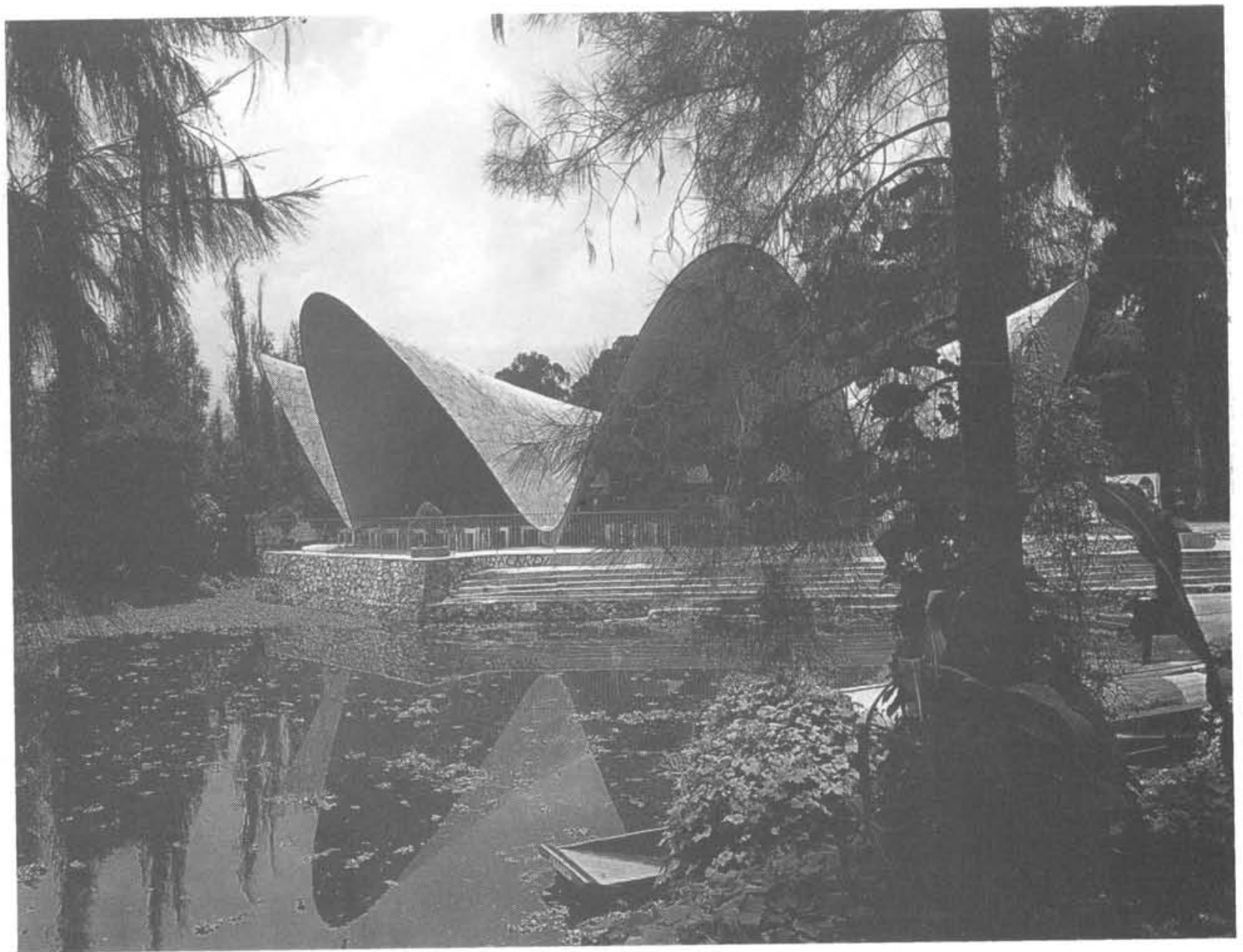

"Idolos de madera a los que nada falta porque sus almas son tan pobres que no preguntan por la lluvia y el brillo del sol porque no tienen nada que requiera cuidado"

La ausencia de una mirada interior, hacia los espacios de la arquitectura, nos inclina a entender estos lugares como objetos de fruición o escenarios de arrogantes decorados, y a los arquitectos como distribuidores de formas admitidas y tipologias consagradas, en lugar de objetos de civilización y espacios para la vida, como construcciones sintesis de lo real y lo imaginario.

La arquitectura desde la lectura de sus episodios actuales está entretenida en asumir la servidumbre del

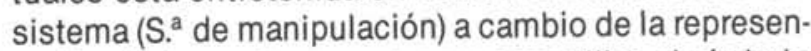
tación de lenguajes que desconoce utiliza el simbolo con una actitud animista, según la cual la forma, una vez construída como mercancia aleja los temores y gratifica la existencia. "El arte es una de las actividades fundamentalmente necesarias y especificas del hombre que vive en sociedad. Permite no sólo anotar y comunicar representaciones adquiridas, sino también descubrir nuevas. No es comunicación, sino institu- ción. No es lenguaje, sino sistema de significación" (*). ¿Podemos aceptar como sistema de significación los ámbitos espaciales o la iconografía de objetos banales del apartamento - Kitsch - norteamericano, o tal vez los corredores penitenciarios, o el estilo cuartelero de los estetas italianos? Podremos entender como espacios institucionales las aberraciones geométricas de las cofradias de "escarzanos y escalenos" de los arquitectos pequeños burgueses, o bien los ideales interiorizados del espiritu prusiano, tan elocuentemente expuestos en los escenarios del IVA Berlinés o el Paris socialista... espíritu que se pretendia haber abatido en 1945. El resultado no debe extrañar en la "arquitectura de imagen", pues se utiliza de ella lo que se sabe o se pretende saber, se descontextualiza y desarticula de su lugar y contenido. La imagen no es el concepto, ni refleja lo real percibido; el proyecto arquitectónico se establece por tanto en los dominios de la alusión, cuya función primordial está destinada a enfatizar el "aura" perdida de sus "creadores" ¿Acaso la alusión puede entenderse como una nueva forma de representación?

(*) P. Francastel - La figura y el lugar. Ed. M. Avila. 
No se trata por tanto de dar nuevos contenidos a la cualidad del espacio, sino de proporcionarle una nueva composición, esto es, una mirada en el contexto de esta segunda naturaleza técnica. La redundancia de formulaciones gráficas por las que discurre hoy la imaginación arquitectónica concluye en un abatimiento de la forma; no se puede dibujar más porque el propio dibujo destruye. El proyecto se disuelve en una concatenación de gráficas, de testimonios geométricos ortogonales, triangulados..., que acuden a instalarse en el territorio inconexo de lo "ecléctico", tabla de salvación y justificación del sentimiento agotado en los finales de siglo (Viena aún se exhibe en el Pompidou entre "Tu. les azulados" y casacas enmohecidas del último $\mathrm{H}$. Hoellins).

Pensamiento, espacio arquitectónico y realidad dista por el momento de ser una terna coherente y contextualizada ¿Podremos achacarla a la dificultad de la expresión gráfica (lenguaje de lo arquitectónico), para aceptar la realidad y manifestar sus contradicciones? Resulta prematura cualquier determinación, pues apenas abunda material crítico en torno al lenguaje de la arquitectura, desde supuestos de esta mirada perceptiva. Se apuntaron algunos destellos entre los constructivistas y futuristas, hoy esquilmados por depredadores de los archivos de la historia, lamentablemente reducidos a un eslogan de signos con los que hacer mercancia de modernidad.

El poder que asumen los medios de comunicación grá. fica proclaman que la apariencia de la imagen reproduce la forma de realidad espacial, como ocurre en el lenguaje político donde la palabra vacia de significado pretende asumir los contenidos de libertad. No parece que resulte excesivamente moralizador insistir en la necesidad de recuperar la forma de la arquitectura en su sentido más primario y original: comienzo e iniciativa, también invención, configuración y solidificación, es decir, rescatar a la arquitectura de las servidumbres del sistema, de los arquetipos del inconsciente programados y entregarla a su verdadera dimensión constructiva.

Resulta evidente en el ámbito de la espacialidad arquitectónica que el "proyecto moderno", que hoy contemplamos, ha consagrado a la comunicación como un valor, la apariencia formal como un medio, la instrumentalidad gráfica como mensaje. Esta doctrina nos explica, en parte, que la arquitectura de la ciudad se llegue

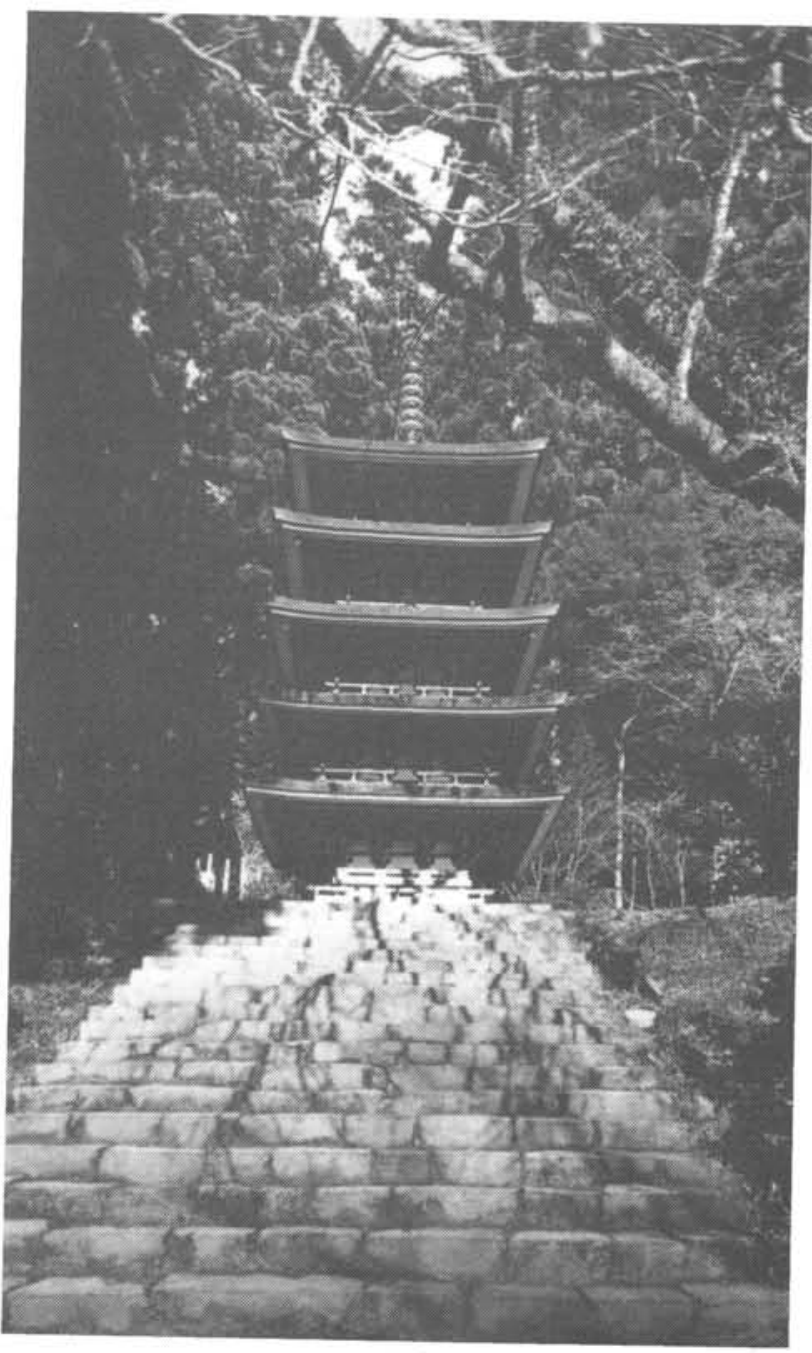

a entender como una comunicación de "apariencias", como ejercicios compositivos basados en la crónica del bagaje gráfico, como construcciones "láviles" destinadas a ser percibidas por la mirada blanda (Look light) de nuestra época.

El encuentro del hombre de hoy, en estos espacios del último proyecto moderno, está eclipsado por el brillo del papel couché de la linotipia; la emoción que de ellos emana se encuentra agotada por las filigranas de historias ya narradas; la "fascinación" de sus fachadas reproducen el hedor de la reliquia, insensible a la materia, adictos a lo circunflejo de la forma, estos arquitec. tos invaden la arquitectura de la ciudad con arrogantes pedestales, que aspiran a ocupar los templos vacíos de la forma. 